Editorial

\title{
Scenarios and Indicators for Sustainable Development: Towards a Critical Assessment of Achievements and Challenges
}

\author{
Joachim H. Spangenberg ${ }^{1,2}$ (1) \\ 1 Sustainable Europe Research Institute SERI Germany, 51103 Cologne, Germany; \\ Joachim.Spangenberg@seri.de \\ 2 Helmholtz Centre for Environment Research UFZ, 04318 Leipzig, Germany
}

Received: 11 February 2019; Accepted: 12 February 2019; Published: 13 February 2019

The global ecosphere is a complex, evolving system, and the anthroposphere another, more rapidly evolving one. Globalization and telecoupling are enhancing their complexity, and even more that of the coupled socio-ecological system [1]. Sustainable development as a global normative development concept and as defined by the 2030 Agenda and its Sustainable Development Goals (SDGs) adds another level of complexity [2]. As a result, the demand for tools to identify transformative innovations, assess future risks, and support precautionary decision-making for sustainability is growing by the day in business and politics. Scenarios are a means of simplification, reducing real-world complexity to a potentially high but limited number of factors, analyzing their interactions, and supporting policy formulation [3]. However, they are not "objective" representations of reality but to a certain degree cannot but reflect orientations and norms held by their authors [4].

While political or management demands can emerge rather spontaneously, scenario development takes time- the demand for climate scenarios with a maximum $1.5^{\circ} \mathrm{C}$ of global warming took the Intergovernmental Panel on Climate Change IPCC by surprise and required almost three years to be fulfilled. Integrated models are at the core of the IPCC $1.5^{\circ}$ report, but also used all over the world for sustainable development assessment and strategy development. Nevertheless, they (and in particular the economic computable global equilibrium (CGE) models most of them incorporate) are criticized for a lack of transparency, implicit normative assumptions, technical insufficiencies, political bias and an inability to capture the stark and structural changes of the effect-driving mechanisms, in particular the roles of uncertainty and of non-linearities (tipping points). These and other shortcomings limit their reliability as basis for policy development-for instance, the IPCC's model-based warnings have become more severe with every new report. Is this only due to newly discovered facts, or can one of the reasons be the implicit habit of scientists to avoid type 2 errors (claiming a relationship when it does not exist) at the expense of making type 1 errors (not confirming the existence of a relationship when it exists)? [5] What roles do other habits and routines, and the worldviews of scholars, play in the assumptions made and the interpretations given, in particular in the CGE components? At least the latest IPCC scenarios, assuming ongoing economic growth in affluent countries at the cost of a greenhouse gas overshoot, indicate that scholarly beliefs can trump physical necessities-the economists involved refused to test any scenario analyzing how a no-growth, steady state, or even degrowth economy would work out for social structures, economic prospects, and community flourishing [6]. This is no coincidence but in line with usual procedures of standard economics: so far, the only models used to inform policy choices are at the "optimistic" end of the scale, and within them, functions and parameter choices are taken so "extreme" conclusions are avoided, such as immediately stopping all GHG emissions being the economically optimal policy [7] as this reflects the willingness to pay to avoid future damage [8]. 
From an environmental point of view, the biophysical perspective must be the basis of scenario development, with social and economic impacts the dependent variables to be managed politically. In particular, "the social" as one of the core dimensions of sustainable development includes the effects and dynamics of public orientations including values and preferences, decision-making mechanisms including equity, gender issues, power statures and democracy, and implementing organizations, their roles, and functions [9] —all factors which often lend themselves better to qualitative description (at best ordinal scale measurement as used by the IPCC and its biodiversity pendant, the Intergovernmental Science-Policy Platform on Biodiversity and Ecosystem Services IPBES) rather than quantification $[10,11]$.

Similar questions apply to indicators. They are not only major tools for communicating scenario results but also underpin monitoring selected real-world trends recognized as worth doing so, support communication about monitoring and modelling results and ultimately, aid decision making. However, which parameters are chosen for monitoring and which yardsticks (indicator methods) are applied in doing so often has more to do with established measurement methods, data availability (in particular time series), and data consistency than with which problems are currently of highest importance, politically, ecologically, socially, or economically. If newly emerging trends are not subject to reporting due to missing data time series, this implies that no problem recognized as such less than a quarter century ago can make it into the reporting mechanisms. Similarly, if the data collection focuses on parameters that have been considered relevant under past theoretical assumptions, there is a risk that if such theories are falsified or recognized as outdated, structurally unchanged indicator reports will point in a wrong direction.

As a purposive sustainability transition requires environmental innovation and innovation policy, in the first paper in this Special Issue, Daniel Hausknost and Willi Haas discuss the potential and limitations of three dominant strands of literature, the multi-level perspective on socio-technical transitions (MLP), the innovation systems approach (IS), and the long-wave theory of techno-economic paradigm shifts (LWT). They show that in all three approaches, normative societal goals like sustainability are sidelined, and neither strong directionality nor incumbent regime destabilization are societally steered. To overcome these obstacles to the dominant transition theories, they call for new political institutions to make normatively guided selections. Such institutions for transformative innovation are needed to improve the capacities of complex societies to make binding decisions in politically contested fields (Contribution 1). Obviously, for all past successes, scenario development, model building, and deriving indicators deserve and require a permanent critical assessment and in particular, a critical self-reflection of scholars, if they are to maintain and enhance their usefulness in supporting better decision-making in an increasingly complex world. Joachim H. Spangenberg illustrates the deep embeddedness of scenarios and their results in underlying, but not always explicit, theories and how such assumptions shape results and recommendations (Contribution 2). As the scenarios he analyzes are quite archetypical (they come from a large, EU-funded biodiversity research project called ALARM), the lessons-to-be-learnt and the call for reflection on basic assumptions apply to sustainability scenarios more generally. While in the economic scenarios he used, physical parameters like material flows could only be represented indirectly, the more recent ground-breaking work by Giampietro and his team permit the direct integration of energy and emissions in physical terms with labor and economic parameters. Louisa Jane Di Felice, Maddalena Ripa and Mario Giampietro show that by not accounting for the emissions associated with building and maintaining new infrastructure (funds), and particularly those required to increase grid flexibility, the scenarios currently used to inform decarbonization narratives in the EU are missing a key part of the picture (from a biophysical perspective, decarbonization is not just a matter of replacing carbon-intensive with carbon-neutral electricity flows but is also a matter of funds, which in turn are associated with GHG emissions) (Contribution 3). Their analysis suggests that scenarios informing decarbonization policies in the EU are overly optimistic and may lead to an underestimation of the urgency of reducing overall energy consumption to stay within safe carbon budgets. In the following paper of this Special Issue, Anke 
Schaffartzik and Marina Fischer-Kowalski widen the perspective to the international level, where the transition from traditional renewable to "modern" fossil energy carriers is still the dominating trend-which, due to globally limited supplies and sinks, is not an indefinite option. What affluent and transitioning countries alike need is a sustainability transformation that would change far more than patterns of energy supply and use, rather than only a "Big Push" for renewable energy within pockets of the fossil energy system. They argue that where this far-reaching change requires pushing back against the fossil energy system, the energy underdogs-the latecomers to the fossil energy transition-just might come out on top (Contribution 4).

Turning from scenarios to indicators in the second part of the Special Issue, virtually the same challenges continue to haunt scholars and worry the invited authors. Indicators simplify even more than models, but they can make communication much easier. The question then is how to strike a balance, ensuring that the information lost by indicator design makes the result easy to communicate but not potentially misguiding. In particular, in the age of "fake news" and "alternative truths", simplifications have become suspicious. How can scholars guarantee and demonstrate that their indicators are not misguiding, intentionally or unintentionally, but are reliable and trustworthy scientific results? This is the starting point of Simon Bell and Stephen Morse as they discuss past indicator developments, giving a critical overview of the field as it is today plus a future outlook (Contribution 5). The latter step, rethinking the current state of sustainability indicators and building visions that could reshape the indicator reality is the starting point of Tomás B. Ramos. Based on a critical analysis of a set of challenges and opportunities, he discusses what could be some of the new frontiers and paradigms in sustainability indicators, focusing on three main criteria of valuation: relevancy, feasibility, and societal impacts (Contribution 6). While Ramos promotes new ways of thinking and doing, responding to new global and local paradigms and using transdisciplinary innovations, Rainer Schliep, Ulrich Walz, Ulrich Sukopp, and Stefan Heiland have a different problem to deal with: on invitation by the German Ministry for the Environment and the Federal Agency for Nature Conservation, they were developing new indicators for policy advice and were confronted with two unsatisfactory options. First, a data-driven, bottom-up approach determines indicators primarily by the availability of suitable data. Second, indicators can be developed by a top-down approach, on the basis of political fields of action and related normative goals. While the bottom-up approach might not meet the needs of up-to-date policy advice, the top-down approach might lack the necessary empirical underpinning. For their project, they developed a combined approach that can be considered successful, despite some remaining gaps (Contribution 7). In conclusion, the scientific accuracy of the indicators, the availability of data, and the purpose of policy advice have to be well-balanced when developing indicator systems.

Such questions have been, implicitly and explicitly, a matter of dispute in the process of developing and agreeing on indicators to monitor SDG implementation, and a critical examination of reporting so far (several such major global assessments have already appeared) can be considered an appropriate means to identify the likely significant room for improvement. Svatava Janoušková, Tomáš Hák, and Bedřich Moldan highlight that while the current structure of the SDGs has provided a rather firm policy framework, the goals and targets have mostly been operationalized by indicators (Contribution 8). They demonstrate that without a procedurally well-designed conceptual framework for selecting and/or designing indicators, the results of SDG assessments may be ambiguous and confusing. The current SDG indicators tend to fall short of this condition. Johannes Buhl, Christa Liedtke, Jens Teubler, Katrin Bienge, and Nicholas Schmidt also start with the SDGs, and in particular with Goal 12 on sustainable production and consumption, but zoom down to the household level. One indicator named in the SDG for resource use is the material footprint, but a method and disaggregated data basis differentiating the material footprint for production and consumption according to, e.g., sectors, fields of consumption, as well as socioeconomic criteria, does not yet exist. In the search for a solution, they present two microdata-based methods and their results, namely an indicator based on representative expenditure data in Germany and an indicator based on survey 
data from a web tool (Contribution 9). Indicators based on microdata are particularly useful as they make sure that indicators can be disaggregated by socioeconomic characteristics like age, sex, income, or geographic location.

Like the previous authors, Patrizia Modica, Alessandro Capocchi, Ilaria Foroni, and Mariangela Zenga faced data collection problems when assessing the impacts of the European Tourism Indicators System (ETIS) during the period 2013-2016 in a case study in South Sardinia (Contribution 10). With insufficient stakeholder involvement in the implementation process, they find that the objectives of promoting economic prosperity, social equity, cohesion, and environmental protection require an adaptive management approach, including adapting these standardized indicators to different territorial contexts. In particular, the pioneering sustainable tourism performance measurement system (STPMS) can be adapted to meet local needs. Their experience illustrates another challenge to indicator systems: to allow for comparisons, they should be standardized as much as possible, but to be locally meaningful and gain the attention of citizens and decision-makers, they must be adapted to local circumstances. Concepts with standardized categories at higher levels of abstraction, to be filled with context-specific and problem/concern-driven local indicators, have been suggested but so far have not been realized [12], not least because decision-makers appear to have a strong preference for quantitative over semi-quantitative or qualitative indicators-a fallacy of misplaced precision.

\section{List of Contributions:}

1. Hausknost, D.; Haas, W. The Politics of Selection: Towards a Transformative Model of Environmental Innovation.

2. Spangenberg, J.H. Behind the Scenarios: World View, Ideologies, Philosophies. An Analysis of Hidden Determinants and Acceptance Obstacles Illustrated by the ALARM Scenarios.

3. di Felice, L.J.; Ripa, M.; Giampietro, M. Deep Decarbonisation from a Biophysical Perspective: GHG Emissions of a Renewable Electricity Transformation in the EU.

4. Schaffartzik, A.; Fischer-Kowalski, Marina. Latecomers to the Fossil Energy Transition, Frontrunners for Change? The Relevance of the Energy 'Underdogs' for Sustainability Transformations.

5. Bell, S.; Morse, S. Sustainability Indicators Past and Present: What Next?

6. Ramos, T.B. Sustainability Assessment: Exploring the Frontiers and Paradigms of Indicator Approaches.

7. Schliep, R.; Walz, U.; Sukopp, U.; Heiland, S. Indicators on the Impacts of Climate Change on Biodiversity in Germany-Data Driven or Meeting Political Needs?

8. Janoušková, S.; Hák, T.; Moldan, B. Global SDGs Assessments: Helping or Confusing Indicators?

9. Buhl, J.; Liedtke, C.; Teubler, J.; Bienge, K.; Schmidt, N.. Measure or Management?-Resource Use Indicators for Policymakers Based on Microdata by Households.

10. Modica, P.; Capocchi, A.; Foroni, I.; Zenga, M. An Assessment of the Implementation of the European Tourism Indicator System for Sustainable Destinations in Italy.

Conflicts of Interest: The authors declare no conflict of interest.

\section{References}

1. Haberl, H.; Fischer-Kowalski, M.; Krausmann, F.; Martinez-Alier, J.; Winiwarter, V. A Socio-metabolic Transition towards Sustainability? Challenges for another Great Transition. Sustain. Dev. 2011, 19, 1-14. [CrossRef]

2. United Nations General Assembly. Transforming Our World: the 2030 Agenda for Sustainable Development; Resolution 70/1, Document A/RES/70/1, 17th session agenda items 15 and 116, adopted by the General Assembly on September 25th; United Nations: New York, NY, USA, 2015.

3. Alcamo, J. Scenarios as Tools for International Environmental Assessments; EEA Expert Corner Report 'Prospects and Scenarios' No. 5; Office for the Official Publications of the European Communities: Luxembourg, 2001.

4. Spangenberg, J.H. Looking to the Future: Finding Suitable Models and Scenarios. In Towards the Ethics of a Green Future. The Theory and Practice of Human Rights for Future People; Düwell, M., Bos, G., van Steenbergen, N., Eds.; Earthscan from Routledge; Taylor \& Francis Group: Abingdon, UK, 2018; pp. 48-65.

5. EEA European Environment Agency. Late Lessons from Early Warnings: the Precautionary Principle 1896-2000; Environmental Issue Report No. 22; Office for the official publications of the European Communities: Luxembourg, 2001. 
6. Kurz, R.; Spangenberg, J.H.; Zahrnt, A. IPCC-Report Global Warming of $1.5^{\circ} \mathrm{C}$ : Das fehlende Szenario "Klimaschutz ohne Wachstum". Ökologisches Wirtschaften in press.

7. Held, H. Entscheidungen unter Unsicherheit in komplexen Systemen. In Klimawandel in Deutschland; Brasseur, G., Jacob, D., Schuck-Zöller, S., Eds.; Springer Nature: Gland, Switzerland, 2017; pp. 305-311.

8. Weitzman, M.L. On Modeling and Interpreting the Economics of Catastrophic Climate Change. Rev. Econ. Stat. 2009, 91, 1-19. [CrossRef]

9. United Nations. Earth Summit: Agenda 21, the United Nations Programme of Action from Rio; United Nations: New York, NY, USA, 1993.

10. IPCC Intergovernmental Panel on Climate Change. Climate Change 2013: The Physical Science Basis; Cambridge University Press: Cambridge, NY, USA, 2013.

11. Díaz, S.; Pascual, U.; Stenseke, M.; Martín-López, B.; Watson, R.T.; Molnár, Z.; Hill, R.; Chan, K.M.A.; Baste, I.A.; Brauman, K.A.; et al. Assessing nature's contributions to people. Science 2018, 359, $270-272$. [CrossRef] [PubMed]

12. Spangenberg, J.H. Institutions for sustainable development: Indicators for performance assessment. In Governança par el Desenvolupament Sosteible; Gobernidad de Catalunya, Institut Internacional de Governabilitat IIG, Eds.; IIG: Barcelona, Spain, 2002; pp. 133-162.

(C) 2019 by the author. Licensee MDPI, Basel, Switzerland. This article is an open access article distributed under the terms and conditions of the Creative Commons Attribution (CC BY) license (http:/ / creativecommons.org/licenses/by/4.0/). 